\title{
Dynamic-based Learning: a Novel Approach for Higher Education during COVID-19
}

\author{
Arnon Jumlongkul ${ }^{1}$ \\ Address: ${ }^{1}$ School of Medicine, Mae Fah Luang University, Chiang Rai, Thailand 57100 \\ E-mail: arnon.jum@mfu.ac.th, arnonjumlongkul@gmail.com \\ ORCID number of the corresponding author: https://orcid.org/0000-0002-4333-7186
}

\begin{abstract}
Purpose: Now traditional lecture-based teaching and learning have been affected by the COVID-19. The objectives of this article are to design the novel educational technique called 'dynamic-based learning' (DBL) that provides the combination of online teaching-learning methods and student's creativity, to evaluate primary dynamic-based learning function, and to propose dynamic-based learning for higher education.

Methods: DBL composes of four steps, including, preparation, homework, classroom, and evaluation, which was designed, and taught in medical and dental schools. Online support materials included mobile phone, email, Facebook Messenger, Line Messenger, Cisco Webex, and Zoom Meetings applications were recruited for this novel method.

Results: A total of 32 third-year medical students and 26 sixth-year dental students was treated by DBL similarly. three subjects, including, Innovation in Dentistry, Basic Medical Research, and Principles of Pathology and Forensic Medicine were selected in this article. The results showed students could create their knowledge, ideas, and creativity during the online classes.

Conclusion: DBL can be used as an alternative learning mode during the COVID-19 crisis. The benefits of DBL also include high flexibility, dynamic process, active learning, and high creativity. DBL should be tested with other disciplines such as engineering school, laws school, health sciences school, and should be compared with other traditional teaching and learning modes in the future. This method may support the global higher education systems to move forward the COVID-19 pandemic to set a novel standard of a future normal.
\end{abstract}

Keywords: COVID-19, dynamic-based learning, higher education, interactive learning, online classroom

\section{Declarations}

Funding: The material and financial support was provided by Mae Fah Luang University.

Conflicts of interest/Competing interests: Not applicable

Availability of data and material: Not applicable

Code availability: Not applicable

Authors' contributions: Not applicable

\section{Introduction}

The outbreak of the COVID-19 pandemic has interfered and forced all professionals to adapt their routines to serve social distancing and the new normal. As the situation being, traditional lecture-based teaching and learning have been affected by COVID-19 inescapability. Coming of online learning also is of the most valuable player. In biomedical sciences, some traditional teaching and learning methods, except lecture-based learning (LBL), including, problem-based learning (PBL), case-based learning (CBL), and team-based learning (TBL) have been very popular methods in medical as well as dental schools. Some studies showed PBL, CBL, and TBL students could express their efficiency higher than LBL students in multi-aspects, for instance, problem-solving ability, clinical diagnosis ability, knowledge, learning attitude, and learning skill (Alhazmi \& Quadri, 2020; Chen et al., 2018; He et al., 2018). However, each educational method has pros and cons when using it individually. Therefore, an alternative way to overcome learning barriers is to combine multi-techniques during class such as PBL-CBL combined teaching, and modified TBL 
within PBL medical curriculum (Burgess et al., 2018; Zhao, 2020). To promote the student's learning outcomes, students should receive and explore instructional material before class, then, discuss it within their classroom. This procedure also called a 'flipped classroom', which can be amalgamated with PBL and TBL methods, but not limited to all those learning methods. The flipped classroom could encourage higher learning outcomes when students faced class time, compared to the non-flipped classroom's learners (Hu et al., 2019; Nishigawa et al., 2017; van Alten et al., 2019).

As part of higher education, the formal educational systems have been shut down according to the global lockdown policies and transformed into online teaching-learning modes. In India, many different online teaching modes have been used by both teachers and students such as Google Classroom, Zoom/ Skype/ Google Meet/ Cisco WebEx, Webinar, YouTube Videos, YouTube/Facebook Streaming, WhatsApp/ Telegram, Telephonic Conversation, Email, etc (Mishra et al., 2020). When using the Strengths, Weaknesses, Opportunities, \& Challenges (SWOC) analysis for considering e-learning modes during the time of crisis, the results showed the strengths of e-learning methods included time \& location flexibilities, ready for wide audiences, courses \& content availabilities, and sudden feedback. Some weaknesses, for example, loss of direct communication and human touch between the learner and the teacher, technical difficulties, time management, distraction, and lack of attention were identified. The opportunities also included a lot of scope for innovation, flexible program design, strengthen skills, unlimited users by aging, and radical transformation of pedagogy. Finally, the Challenges of e-learning consisted of inequitable ICT infrastructure, digital illiteracy, educational quality, and technology cost and antiquity (Dhawan, 2020). In China, a case study of online teaching in higher education concluded five high-impact principles of online education, including, the appropriate relevance between teaching content and academic readiness, effective delivery of online instructional content, sufficient academic support, high-quality participation, and last, the preparation for an unexpected accident that will occur during the teaching operation (Bao, 2020). Online teaching platforms in UK medical schools could give flexibility benefits to medical students whereas poor internet connection, as well as family distraction, was the common barriers during the educational processes. However, when considering an experience of online surgical learning, undergraduate medical students in Sri Lanka agreed that it could improve their clinical sense when using multi-consultant panel discussions, while most medical students in the UK felt online teaching could not overcome or replace clinical teaching. They also could not receive practical clinical skills sufficiently (Chandrasinghe et al., 2020; Dost et al., 2020).

According to Bloom's taxonomy levels, which also date back to 1956, created originally by Benjamin Bloom, the revised Bloom's taxonomy model explained the hierarchy of cognitive skills ranging from lower- to higher-order skills, which can be classified into six categories, including, remember, understand, apply, analyze, evaluate, and create, respectively. To encourage students to reach the highest Bloom's taxonomy level, project-based learning can be used as a facilitator of this process when amalgamated with flipped Bloom's taxonomy model, which instructional materials are introduced to students as their homework to support remembering and understanding levels, then, students and lecturers must work together within a classroom for learning the higher-order skills (Adams, 2015; Folayan \& Ademiloye, 2020). Nevertheless, this model was applied and succeeded in an engineering class, but also project-based learning approach in medical schools usually limits such a research subject that needs a long time course ( $\mathrm{Si}, 2020)$. Consequently, the challenge is to incorporate a flipped classroom with other learning methods that provide student's learning outcomes to get to the highest hierarchy of Bloom's taxonomy levels.

Nowadays we are waiting for a new solving problem educational method for COVID-19 crisis management that can amalgamate the appropriate proportion of among the combined teaching-learning methods, digital and online educational systems, and also the highest student's learning outcomes according to the hierarchy of Bloom's taxonomy. Therefore, the purposes of this article are to design the novel educational technique called 'dynamic-based learning' (DBL), to evaluate primary DBL function when applied with medical and dental schools during the COVID19 spreading, finally, to propose the development approach of DBL for higher education in the new era.

\section{Methods}

The author is a lecturer and a medical examiner at the School of Medicine, Mae Fah Luang University, Thailand. I have taught or co-taught both Doctor of Medicine Program and also Doctor of Dental Surgery Program. The number 
of students of each class is not over than 32 persons following the limit of admission rate. Three subjects, which were taught from April to June 2020, were selected as the DBL representatives. The detail of each subject is shown below;

Innovation in Dentistry: This subject provides for year 6 dental students. 'Introduction to Medical and Dental Innovation' and 'Innovative Dental Research' topics were included.

Basic Medical Research: This subject provides for year 3 medical students. 'Introduction to Basic Medical Research' and 'Innovative Medical Research' topics were included.

Principles of Pathology and Forensic Medicine: This subject provides for year 3 medical students. Topic 'Forensic Medicine' was included.

All topics did not take more than three hours, except the 'Forensic Medicine' topic that was extended to seven hours according to the role-play section, which was conducted as the trial court simulation.

This article is only a sharing of personal experiences during the COVID-19 situation. I also taught DBL in all of my classes solely without the comparison of other face-to-face traditional learning methods, for instance, PBL, CBL, and TBL. Therefore, the ethical review was not a necessity.

\subsection{Designing DBL concept}

The author defined that DBL is 'a type of student-centered learning that is designed to support the dynamic educational process. Students also use an appropriate time with suitable resources to generate their answers before class, then, present their ideas in the classroom. Teachers only play as a coach and clarify students' blind spots profoundly. Students and teachers show dynamic-alternated roles during the classroom to promote the educational objectives involve knowledge, attitude, and creativity'.

The process of DBL is shown in Figure 1. In the preparation step, the curriculum design of each subject was done. Objectives were designed for making students achieve all educational objectives following Bloom's taxonomy. The author prepared the classroom handouts, including, set of questions that asked for both knowledge and creativity, lecture handouts, credible online academic sources for students, and other related documents. Eighty percent of the data available was provided by the author while the rest might be searched by students, which remained for creative spaces and also lifelong learning skills.

The second step is a homework assignment. The author announced all documents at least one week before attending class. Students were divided into multi-groups. The number of the group also correlated with the duration of each topic. Students then formulated their responsibility and contacted the teacher by themselves. Some questions or projects were designed to generate creativity among students and there was no correct answer, but also students must search for articles to collect data and synthesize their knowledge before the presentation time. This method was a high of flexibility that the teacher can switch the teaching and learning techniques between PBL, CBL, TBL, projectbased learning, outcome-based learning (OBL), or other technique based on the flipped classroom into DBL class.

The third step is a classroom debate. All students' groups were assigned to be a teacher and the teacher also played as a student. Students must present their work and make everyone understand what were they presenting. This situation is a highly dynamic process because the teacher might evaluate the details presented, and also the understanding among the listeners. If the process showed some mistakes, then, the teacher might act as a coach to promote a good learning condition, for example, asking the pain point of those topics, describing some details that were abandoned, cheer up, and encouraging. Knowledge management would occur during class through the interactive listening processes.

The evaluation step started when the teacher asked for comment, then, students shared their ideas and their perspectives. The teacher also pointed some issues of the topic discussed in the different aspects, for example, when the author taught in the subject of Reproductive System II, topic 'Sexual Assault and Laws', some questions were given to the class, including, "What is the appropriate rate of penalty for the rapist?", "Why do you think capital punishment is the best solution?", "What is the most significant factor than can change someone to be a criminal?", "Have you ever heard restorative justice, which can be applied to the rape cases?", "Can you choose the appropriate way to manage the rape crisis in Thailand?", etc. This process desires to make transformative learning (TL) through 
critical reflection between the lecturer and learners (Eschenbacher \& Fleming, 2020). The teacher summarized the class and sent feedback together. Finally, the revised version will be planned for the next class.

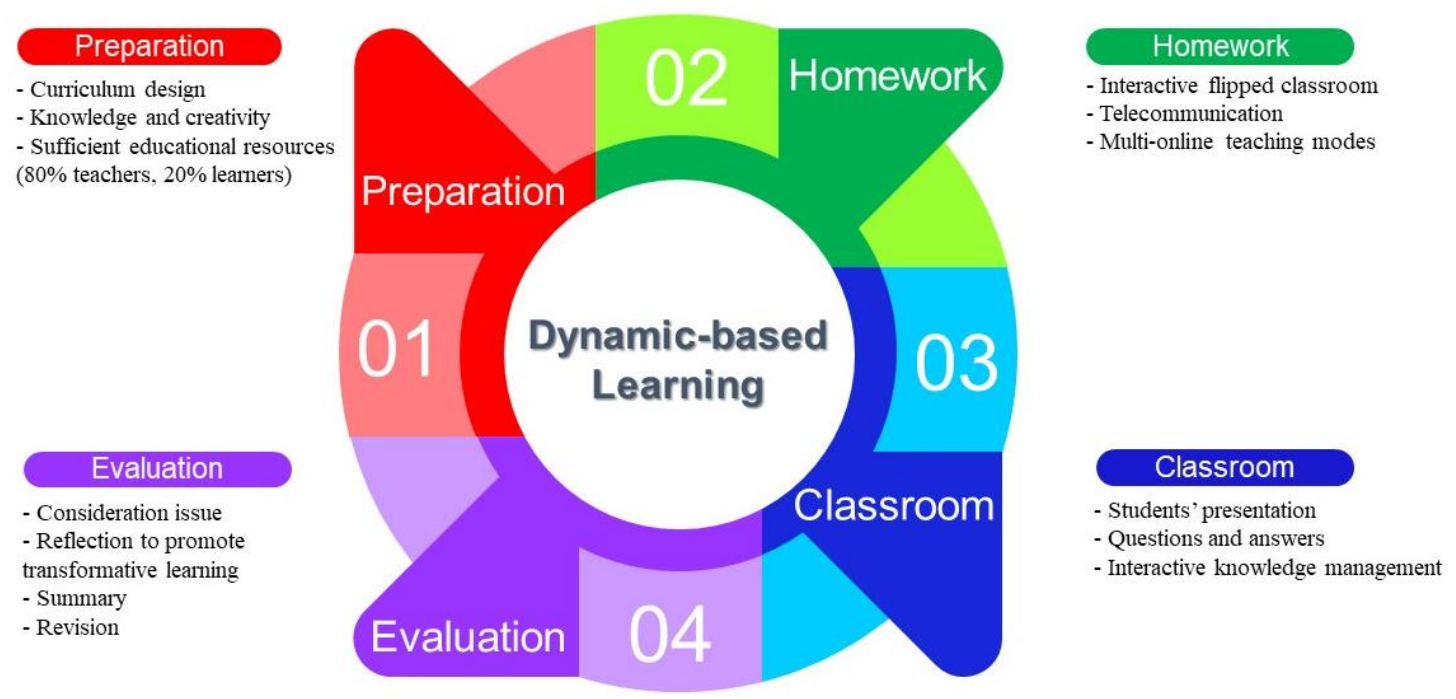

Figure 1. Dynamic-based learning process

\subsection{Online material support}

Firstly, all documents were released in Google Classroom by the author. All knowledge questions, that did not reveal within the teacher's documents, were tested with the search engine to make sure that students can access the correct answers. For any questions, students can contact the teacher directly via mobile phone, email, Facebook Messenger, and Line Messenger until the date before attending class. The online classes operated through Cisco Webex and Zoom Meetings applications. The author did not restrict how to make or provide the activities during class, then, students can choose the convenient way to present their works by themselves. Therefore, we can share both knowledge and presentation techniques between the teacher and students. Multi-online support of each teaching and learning step is shown in Figure 2. 


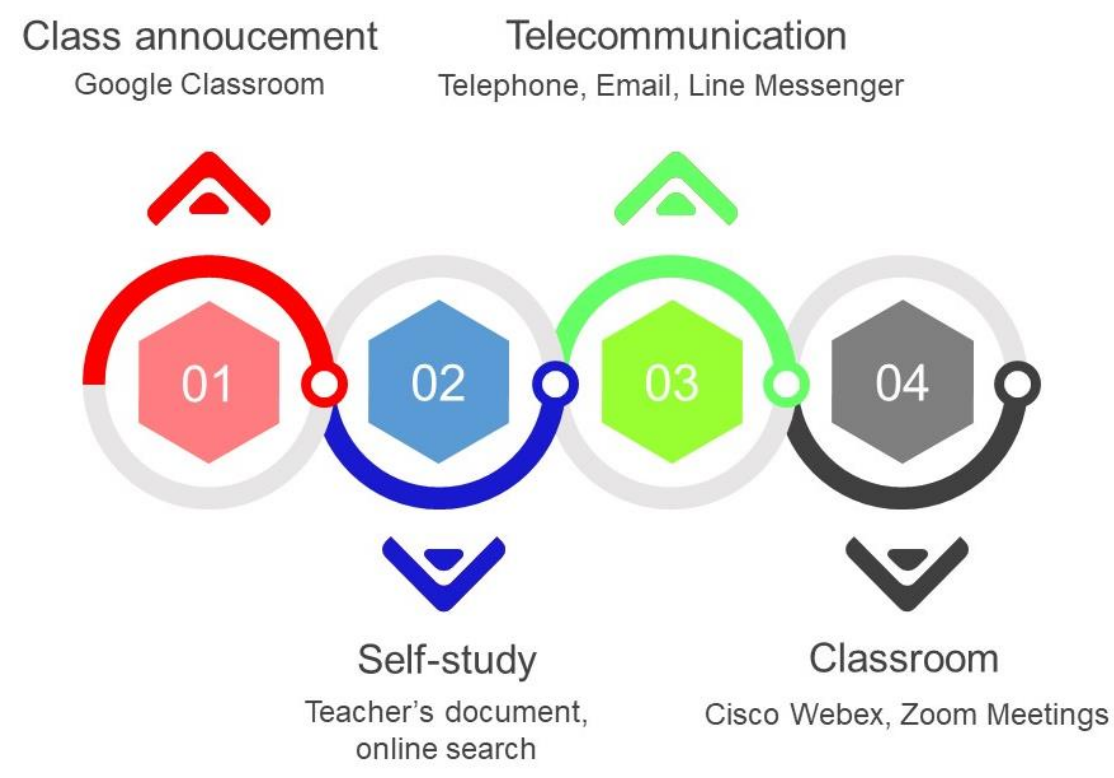

Figure 2. Multi-online teaching and learning support

\section{Results}

A total of 32 third-year medical students and 26 sixth-year dental students was analyzed. All classes were treated by DBL similarly. Essential results are described as follows;

\subsection{Innovation in Dentistry Subject}

In these classes, the main educational methods that were applied, including, project-based learning and flipped classroom. Twenty six-student was divided into five groups, and then, each group was assigned to create an innovative dental research project individually. The scope of presentation for each group included research title, interesting problem, literature review, objective, type of research and innovation, the body of knowledge, multidisciplinary teams, research methodology, human ethics, budget, research funding, marketing plan, type of intellectual property, references, and appendix. Students also received all educational objectives in accordance with Bloom's taxonomy. Before the class presentation, all student groups brought their contents into Google Slides or converted them to PDF files and they also showed those subject matters through Cisco Webex or Zoom Meetings. Students told that applications, which were applied for prototype drawing, also included Procreate and SketchUp. However, some groups interpreted their proposal deviated from handouts because they did not discuss it with the teacher before.

\subsection{Basic Medical Research Subject}

Thirty-two student was divided into eleven groups. In the topic 'Introduction to Basic Medical Research', each group received one question to evaluate their remember and understand, then, they let to create their research question to evaluate the educational objectives that are higher than applying level according to Bloom's taxonomy. PBL, project-based learning, and flipped classroom were the main educational methods of this class.

The second topic 'Innovative Medical Research', which is based on project-based learning and flipped classroom, used the same student group as the previous class. Each group was assigned to create an innovative medical research project individually, which topic is very similar to the Innovation In Dentistry Subject. They used free Google Slides and PowerPoint templates on the website 'Slidesgo' and shared any real-time data using Google Slides. As part of English supplements, they used the application 'Grammarly', which is an automated grammar checker, to help them corrected their article. Almost all student groups could achieve the learning objectives without mistaken interpretation.

\subsection{Principles of Pathology and Forensic Medicine Subject}


Three educational methods, including, PBL, flipped classroom, and role-play were prepared by the teacher whereas CBL was provided by students, but also the teacher determined the scope of a case which would be brought to the class. Thirty-two student was divided into ten groups, then, they were assigned to study teacher's handouts and YouTube Videos. After the discussion of basic knowledge and creative skills, students conducted a case in the online courtroom. The highlight of this class was to express how to take evidence to the court using online communication. Students asked for the court process to the teacher, then, they created dialogues following handouts and presented a stage performance via Cisco Webex.

\section{Discussion}

DBL seems to be a proper technique during the COVID-19 pandemic, the new normal, and also a new future. However, some issues should be of concern. Firstly, in the preparation step, the teacher should prepare all documents before announcing them to Google Classroom to make sure that your resources are sufficient. If students cannot access in the right direction, it means they will achieve for nothing. Twenty percent of data, which students must enter by themselves, should be searched and examined meticulously before the homework step. The teacher should doublecheck all related documents with peer review (if any), which means you must take too much time to create all supplementary documents.

Secondly, in the homework step, the author found some students neglected for consulting any issues that they did not understand. I also cannot tell everyone directly according to the lack of face-to-face mode. To solve this problem, ordering repeatedly with someone, for example, the class president, to repeat the teacher's quote with other students, may be an appropriate way. Your private time should be available for the massive questions that will enter your communication channels directly. I just found sometimes students called me at 10.00 PM a day before class, after that, I announced that everyone should consult me early 06.00 PM, before attending class.

Thirdly, during classroom presentations, the author cannot evaluate the attention level among students. Most of them closed their camera, except who was presenting his task. A study revealed the limitations of online learning, including, unable to teach skills, lack of student feedback, limited attention span, lack of attentiveness, resourceintensive, lack of discipline, and plagiarism among students. The recommendations also included a reduction in cognitive load, increased interactivities, and the use of CBL (Mukhtar et al., 2020). Another challenging issue is the network unstable, which may occur during the class. Therefore, the Wi-Fi systems as well as all online teaching modes should be tested before starting the class.

Fourthly, when the class finished, all classrooms were lack of comments. Even though the teacher can evaluate the understanding of students through their presentation, questions and answers, and interactive learning during the class, but also when the class finished, almost total students did not say some errors or points of improvement. Therefore, reflective activities may be used to manage this situation (Cavilla, 2017). The lecturer should prepare the reflection time, approximately ten minutes before the class left to reflect between students and the teacher. Attitudes and teaching practice are very important instruments in the field of teaching that can make both students and teachers open-minded (Syring et al., 2018). Another benefit during DBL class is that all student groups and teachers receive knowledge, ideas, and creativity of the other parties together.

In the future, DBL should be tested with other disciplines such as engineering school, laws school, health sciences school, etc. However, according to the epidemic situation being, we also cannot compare the DBL method with other traditional teaching and learning modes. For further study, this online program should be studied in the aspect of student's skills, knowledge, creativity, and also transformative learning.

\section{Conclusions}

DBL can be selected as an alternative learning mode during the COVID-19 crisis and maybe involve a new future. The benefits of DBL also include high flexibility, dynamic process, active learning, and high creativity. Students and teachers gain some contents that they also have never known, to overcome their blind spots concurrently. To develop the DBL method, the teacher must have a lot of time, and open-minded is the keyword of this process. The author hopes this online DBL method may support the global higher education systems to move forward with this pandemic. Finally, we will stronger together. 


\section{Acknowledgements}

Teaching and learning materials during the COVID-19 pandemic, including, educational applications, Wi-Fi systems, and the author's laptop computer have been supported by Mae Fah Luang University. The author would like to thank Dr. Roger Timothy Callaghan, MB, ChB, School of Medicine, Mae Fah Luang University for grammatical support and also my lovely medical and dental students for their kindly attention in our classes.

\section{Conflict of Interest Statement}

None.

\section{References}

Adams, N. E. (2015). Bloom's taxonomy of cognitive learning objectives. Journal of the Medical Library Association : JMLA, 103(3), 152-153. https://doi.org/10.3163/1536-5050.103.3.010

Alhazmi, A., \& Quadri, M. F. A. (2020). Comparing case-based and lecture-based learning strategies for orthodontic case diagnosis: A randomized controlled trial. Journal of Dental Education, 84(8), 857-863. https://doi.org/10.1002/jdd.12171

Bao, W. (2020). COVID -19 and online teaching in higher education: A case study of Peking University. Human Behavior and Emerging Technologies, 2(2), 113-115. https://doi.org/10.1002/hbe2.191

Burgess, A., Roberts, C., Ayton, T., \& Mellis, C. (2018). Implementation of modified team-based learning within a problem based learning medical curriculum: A focus group study. BMC Medical Education, 18(1). https://doi.org/10.1186/s12909-018-1172-8

Cavilla, D. (2017). The Effects of Student Reflection on Academic Performance and Motivation. SAGE Open, 7(3), 215824401773379. https://doi.org/10.1177/2158244017733790

Chandrasinghe, P. C., Siriwardana, R. C., Kumarage, S. K., Munasinghe, B. N. L., Weerasuriya, A., Tillakaratne, S., Pinto, D., Gunathilake, B., \& Fernando, F. R. (2020). A novel structure for online surgical undergraduate teaching during the COVID-19 pandemic. BMC Medical Education, 20(1). https://doi.org/10.1186/s12909020-02236-9

Chen, M., Ni, C., Hu, Y., Wang, M., Liu, L., Ji, X., Chu, H., Wu, W., Lu, C., Wang, S., Wang, S., Zhao, L., Li, Z., Zhu, H., Wang, J., Xia, Y., \& Wang, X. (2018). Meta-analysis on the effectiveness of team-based learning on medical education in China. BMC Medical Education, 18(1). https://doi.org/10.1186/s12909-018-1179-1

Dhawan, S. (2020). Online Learning: A Panacea in the Time of COVID-19 Crisis. Journal of Educational Technology Systems, 49(1), 5-22. https://doi.org/10.1177/0047239520934018 
Dost, S., Hossain, A., Shehab, M., Abdelwahed, A., \& Al-Nusair, L. (2020). Perceptions of medical students towards online teaching during the COVID-19 pandemic: A national cross-sectional survey of 2721 UK medical students. BMJ Open, 10(11), e042378. https://doi.org/10.1136/bmjopen-2020-042378

Eschenbacher, S., \& Fleming, T. (2020). Transformative dimensions of lifelong learning: Mezirow, Rorty and COVID-19. International Review of Education. https://doi.org/10.1007/s11159-020-09859-6

Folayan, G. B., \& Ademiloye, I. (2020). Applying Project Based Learning to Flipped Bloom Taxonomy for Deep Understanding in Control Systems. Journal of Electronic \& Information Systems, 2(1). https://doi.org/10.30564/jeisr.v2i1.2023

He, Y., Du, X., Toft, E., Zhang, X., Qu, B., Shi, J., Zhang, H., \& Zhang, H. (2018). A comparison between the effectiveness of PBL and LBL on improving problem-solving abilities of medical students using questioning. Innovations in Education and Teaching International, 55(1), 44-54. https://doi.org/10.1080/14703297.2017.1290539

Hu, X., Zhang, H., Song, Y., Wu, C., Yang, Q., Shi, Z., Zhang, X., \& Chen, W. (2019). Implementation of flipped classroom combined with problem-based learning: An approach to promote learning about hyperthyroidism in the endocrinology internship. BMC Medical Education, 19(1). https://doi.org/10.1186/s12909-019-17148

Mishra, L., Gupta, T., \& Shree, A. (2020). Online teaching-learning in higher education during lockdown period of COVID-19 pandemic. International Journal of Educational Research Open, 100012. https://doi.org/10.1016/j.ijedro.2020.100012

Mukhtar, K., Javed, K., Arooj, M., \& Sethi, A. (2020). Advantages, Limitations and Recommendations for online learning during COVID-19 pandemic era. Pakistan Journal of Medical Sciences, 36(COVID19-S4). https://doi.org/10.12669/pjms.36.COVID19-S4.2785

Nishigawa, K., Omoto, K., Hayama, R., Okura, K., Tajima, T., Suzuki, Y., Hosoki, M., Shigemoto, S., Ueda, M., Rodis, O. M. M., \& Matsuka, Y. (2017). Comparison between flipped classroom and team-based learning in fixed prosthodontic education. Journal of Prosthodontic Research, 61(2), $217-222$. https://doi.org/10.1016/j.jpor.2016.04.003

Si, J. (2020). Course-based research experience of undergraduate medical students through project-based learning. Korean Journal of Medical Education, 32(1), 47-57. https://doi.org/10.3946/kjme.2020.152 
Syring, M., Tillmann, T., Weiss, S., \& Kiel, E. (2018). Do Open-Minded Student Teachers Have More Favorable Attitudes Towards Different Dimensions of Heterogeneity? Journal of Educational and Developmental Psychology, 8(1), 133. https://doi.org/10.5539/jedp.v8n1p133

van Alten, D. C. D., Phielix, C., Janssen, J., \& Kester, L. (2019). Effects of flipping the classroom on learning outcomes and satisfaction: A meta-analysis. Educational Research Review, 28, 100281. https://doi.org/10.1016/j.edurev.2019.05.003

Zhao, W. (2020). Effectiveness of the Problem-Based Learning (PBL) with Case-Based Learning (CBL) Combined Teaching Method in Clinical Practical Teaching of Thyroid Surgery [Data set]. Mendeley. https://doi.org/10.17632/7484XMWK46.1 